\title{
Author Correction: Functional genomics data: privacy risk assessment and technological mitigation
}

Gamze Gürsoy (1D), Tianxiao Li(i), Susanna Liu(i), Eric Ni(i), Charlotte M. Brannon (1) and Mark B. Gerstein (1)

Correction to: Nature Reviews Genetics https://doi.org/10.1038/s41576-021-00428-7, published online 10 November 2021.

In the originally published article, the following acknowledgements were missing: "This study was supported by grants from the US National Institutes of Health (R01 HG010749 to M.B.G. and K99 HG010909 to G.G.). This work is also supported by the A.L. Williams Professorship Fund." This error has been corrected in the HTML and PDF versions of the article.

https://doi.org/10.1038/s41576-021-00440-x I Published online 22 November 2021

(c) Springer Nature Limited 2021 